\title{
MODEL MENTORING DALAM PENGEMBANGAN KARAKTER KEPEMIMPINAN DI KALANGAN GENERASI MUDA GKII TUMAHOH SALAP
}

\author{
Helber, Hengki Wijaya
}

\begin{abstract}
Abstrak
Tujuan dari penulis skripsi ini yakni untuk mengetahui model mentoring yang dilakukan untuk mengembangkan karakter kepemimpinan di kalangan generasi muda GKII Tumahoh Salap. Metode yang digunakan dalam penyusunan skripsi ini adalah metode penelitian kuantitatif dimana Teknik pengumpulan data adalah sebagai berikut: Pertama, penulis penulis melakukan penelitian kepustakaan, yaitu mengumpulkan data dari kamus, bukubuku, artikel dan jurnal. Kedua, penulis melakukan penelitian lapangan dengan membagikan angket kuesioner dan wawancara ke dua puluh reponden untuk memperoleh data di lapangan. Kesimpulan penelitian menunjukan sebagai berikut: Pertama, hasil analisis menunjukan bahwa bentuk mentoring pribadi $\mathrm{X}_{1}$ memengaruhi indikator $\mathrm{Y}_{3}$ paling besar dari antara bentuk mentoring pribadi, yaitu 90,41\% . Pada bentuk mentoring $\mathrm{X}_{2}$ memengaruhi indikator $\mathrm{Y}_{2}$ juga $\mathrm{X}_{2}$ memengaruhi indikator $\mathrm{Y}_{4}$ paling besar dari bentuk mentoring kelompok, yaitu sama-sama 89,16\%. Hal ini menunjukan bahwa kedua bentuk mentoring ini memengaruhi karakter kaum muda gereja GKII Tumahoh Salap. Kedua, Berdasarkan hasil analisis, menunjukan bahwa kaum muda ini memiliki karakter yang baik melalui proses mentoring pribadi. Ketiga, berdasarkan hasil penelitian terlihat bahwa melalui mentoring kelompok kaum mudah ini dapat menunjukan karakter yang baik dalam kegiatan kelompok. Keempat, berdasarkan analisis, mentoring ini memengaruhi kepribadian kaum muda GKII Tumahoh Salap, terlihat melalui mentoring yang dilakukan, kaum muda dapat memimpin pribadi mereka dan dapat memimpin anggota kaum muda yang lainnya. Hasil inilah yang menunjukan bahwa mentoring ini dapat memengaruhi karakter kaum muda menjadi lebih baik.
\end{abstract}

Kata-kata kunci: Model Mentoring, Pengembangan Karakter Kepemimpinan.

\section{Pendahuluan}

\section{Latar Belakang Masalah}

Masa muda adalah masa pencarian jati diri dan juga merupakan masa di mana para pemuda memerlukan sosok teladan yang baik dalam hidupnya. Sosok itu bisa berupa idola atau seseorang yang disukai. Dalam buku Psikologi Perkembangan Anak dan Remaja menyatakan, "Remaja melihat tokoh yang dikagumi, lalu ingin menjadi sama dengan tokoh tersebut." Pernyataan tentang kebutuhan akan sosok teladan tersebut sedang memberikan pandangan kepada gereja atau keluarga bahwa kaum muda sedang membutuhkan nilainilai hidup dari seorang pemimpin dalam lingkungan terdekatnya. Sosok teladan yang

${ }^{1}$ Singgih D. Gunarsa dan Yulia Singgih D. Gunarsa, Psikologi Perkembangan Anak dan Remaja (Jakarta: BPK Gunung Mulia, 2017), 244. 
perlu diteladani oleh kaum muda ini adalah sosok teladan pemimpin yang memiliki karakter Kristus. Pernyataan Yesus mengenai pemimpin berbeda dengan dunia ini, Yesus berkata dalam Matius 20:25-28, tetapi Yesus memanggil mereka lalu berkata: "Kamu tahu, bahwa pemerintah-pemerintah bangsa-bangsa memerintah rakyatnya dengan tangan besi... Barang siapa ingin menjadi besar diantara kamu, hendaklah ia menjadi pelayanmu. sama seperti Anak Manusia datang bukan untuk dilayani, melainkan untuk melayani dan untuk memberikan nyawa-Nya menjadi tebusan bagi banyak orang." Sosok teladan inilah yang seharusnya dimiliki oleh pemimpin gereja masa kini. John, menyatakan dalam jurnal yang berjudul Membangun Karakter Kepemimpinan menyatakan, "kepemimpinan merupakan pengaruh bagi orang lain, pemimpin ideal ialah seorang yang mampunyai karakter terpuji, sehingga orang lain dapat meneladaninya."² Pernyataan inilah yang menunjukan bahwa seseorang pemimpin perlu memiliki karakter yang baik agar dapat diteladani.

Berbicara mengenai sosok pemimpin, dalam penelitian ini, penulis lebih berfokus pada pemimpin dalam konteks Gereja Kemah Injil Indonesia Jemaat Tumohoh Salap. Oleh sebab itu, pemimpin gereja harus mengambil tanggung jawab ini untuk melakukan pembinaan kepada kaum muda dengan cara menjadikan mentoring sebagai program gereja guna mengembangkan karakter kepemimpinan di kalangan generasi muda GKII Tumohoh Salap. Pernyataan Ike Puspitaningrum dalam buku yang berjudul Peningkatan Kualitas Personal dan Profesional Perawat melalui Pengembangan Keprofesian Berkelanjutan menyatakan, "melalui pembinaan mentoring kaum muda dapat belajar untuk mencapai karakter ke titik yang lebih baik." ${ }^{3}$ Penulis yakin bahwa melalui pemimpin gereja, proses pembinaan melalui mentoring ini akan lebih optimal karena para pemimpin rata-rata telah memiliki pengetahuan tentang pentingnya mempersiapkan generasi muda sebagai calon pemimpin yang akan mengemban tanggung jawab pelayanan di masa yang akan datang.

Namun realita yang terjadi ialah para pemimpin gereja GKII Tumohoh Salap lebih banyak memerhatikan pelayanan jemaat secara umum, tetapi tidak pernah merencanakan program pembinaan bagi para pemimpin di kalangan generasi muda. Dalam hal ini pembina pemuda telah mengusahakan suatu pembinaan melalui mentoring yang diterapkan dalam pelayanan pemuda, dan penerapannya telah berjalan dalam jangka waktu kurang lebih tiga tahun. ${ }^{4}$ Mentoring ini dilibatkan dalam pelayanan pemuda seperti dalam Ibadah PA, Ibadah Padang dan Rekreasi kaum muda. ${ }^{5}$ Perlunya gereja memerhatikan hal ini sebagai kebutuhan gereja bahwa gereja perlu pemimpin masa depan. Penulis setuju dengan pernyataan Zetya Inger Anastasia dalam jurnalnya yang berjudul Visi Jemaat GMIT Pola Tribuana Kalabahi terhadap Pemberdayaan Pemuda dari Perspektif Pembinaan Pemuda, yang mengatakan "Tentunya dalam melibatkan kaum muda dalam pelayanan, gereja perlu melakukan pembinaan kepada mereka." ${ }^{\circ}$ Gereja juga jarang melihat hal ini sebagai sebuah kebutuhan darurat yang harus dipenuhi secepatnya. Ketidakpedulian terhadap pengembangan karakter pemimpin di kalangan pemuda ini, bukan saja menghentikan pelayanan gereja di masa yang akan datang, tetapi juga membuat gereja kehilangan anggota jemaat di masa selanjutnya.

\footnotetext{
${ }^{2}$ Fernando Tambunan, "Membangun Karakter Kepemimpinan," Jurnal Teologi Illuminare 1, no. 2 (2014): 21; John MacArthur, Kitab Kepemimpinan (Jakarta: BPK Gunung Mulia, 2011).

${ }^{3}$ Ike Puspitaningrum \& Tri Hartiti, Peningkatan Kualitas Personal dan Profesional Perawat melalui Pengembangan Keprofesian Berkelanjutan (PKB) (Yogyakarta: Budi Utama, 2017), 83.

${ }^{4}$ Tarisa Tangian, Wawancara Oleh Penulis, Makassar, 25 Mei 2019.

${ }^{5}$ Pengurus Pemuda, Wawancara Oleh Penulis, Makassar, 25 Mei 2019.

${ }^{6}$ Zetya Inger Anastasia, "Visi Jemaat GMIT Pola Tribuana Kalabahi terhadap Pemberdayaan Pemuda dari Perspektif Pembinaan Pemuda," (Skripsi, S.Si.Teol, Universitas Kristen Satya Wacana, 2017), 10, http://repository.uksw.edu/handle/123456789/13413.
} 
Gereja mengalami banyak tantangan. ${ }^{7}$ Seharusnya, gereja yang ingin bertumbuh perlu melakukan proses regenerasi pemimpin, dalam hal ini dimulai dari lingkungan pemuda. Kaum muda adalah calon-calon pemimpin masa depan yang akan menjadi salah satu penentu keberhasilan pelayan gereja. ${ }^{8}$ Seperti pernyataan dalam Jurnal Jaffray menyatakan, "Pemimpin harus mempersiapkan regenerasi kepemimpinan yang baik, bahkan mungkin lebih baik dari pada dirinya sendiri." Pernyataan ini menunjukan bahwa perlunya mempersiapkan regenerasi melalui pembinaan untuk mengembangkan karakter kepemimpinan dalam diri kaum muda melalui proses mentoring. Itulah sebabnya gereja perlu melayani atau memuridkan mereka secara khusus seperti yang dituturkan oleh Tuhan Yesus dalam Matius 28:19-20. Penulis setuju dengan pernyataan Ngendam Sembiring, dalam Jurnal Teologi dan Pendidikan Kristiani, "warga jemaat adalah pribadi-pribadi yang perlu bertumbuh dan berkembang menuju kedewasaan rohani. Mutu rohani warga jemaat tidak datang dengan sendirinya tanpa pengajaran dan pembinaan." ${ }^{10}$ Apalagi perubahan dunia dan ancaman penyesatan semakin banyak terjadi, maka sudah pasti gereja akan membutuhkan orang-orang hebat dan kuat yang harus dikaderkan dengan sebaik-baiknya agar mampu mengantisipasi berbagai tantangan pelayanan dalam berbagai dimensi. Sesungguhnya inilah yang akan memampukan gereja untuk bertahan dalam melayani dan tetap mengalami pertumbuhan secara rohani dengan pertolongan dari Roh Kudus.

Dengan melihat permasalahan yang terjadi di atas, maka penulis memandang perlunya proses mentoring guna mempersiapkan calon pemimpin di generasi muda gereja GKII Tumahoh Salap. Hal ini bertujuan agar gereja dapat melahirkan para pemimpin gereja untuk masa yang akan datang. Berdasarkan latar belakang masalah ini, maka penulis terbeban melakukan penelitian untuk menemukan pentingnya mentoring dalam mengembangkan karakter kepemimpinan dan menulisnya dalam sebuah skripsi yang berjudul: MODEL MENTORING DALAM MENGEMBANGKAN KARAKTER KEPEMIMPINAN DI KALANGAN GENERASI MUDA GKII TUMAHOH SALAP.

\section{Pokok Masalah}

Sesuai dengan latar belakang masalah yang sudah penulis uraikan di atas, maka yang menjadi pokok masalah dalam penulisan ini adalah sebagai berikut:

Bagaimana model mentoring dilakukan dalam mengembangkan karakter kepemimpinan di kalangan generasi muda GKII Tumahoh Salap?

\section{Tujuan Penelitian}

Adapun tujuan penulis yang hendak di capai dalam skripsi ini adalah sebagai berikut: Untuk mengetahui model mentoring yang dilakukan untuk mengembangkan karakter kepemimpinan di kalangan generasi muda GKII Tumahoh Salap.

\footnotetext{
${ }^{7}$ Frederik, 69.

${ }^{8}$ Fransisca, 103.

${ }^{9}$ Agus Prihanto, "Peran Proses Mentoring Pemimpin Kaum Muda Bagi Perkembangan Pelayanan Pemuda di Gereja,” Jurnal Jaffray 16, no. 2 (2018), 202.

${ }^{10}$ Ngendam Sembiring, "Mengatasi Degradasi Moral Melalui Pembinaan Warga Gereja," Illuminate: Jurnal Teologi dan Pendidikan Kristiani 1, no. 1 (2018), 28.
} 


\section{Manfaat Penelitian}

Ada banyak manfaat yang akan dihasilkan oleh skripsi ini. Namun sehubungan dengan variabel penelitian yang penulis sampaikan dalam latar belakang masalah, maka manfaat penulisan karya ilmiah ini adalah sebagai berikut:

Pertama, memberi gambaran kepada gereja betapa pentingnya mentoring dalam mempersiapkan calon pemimpin di kalangan generasi muda.

Kedua, untuk memenuhi sebagian syarat-syarat dalam menyelesaikan Stratum Satu (S1) Program Studi Pendidikan Agama Kristen pada Sekolah Tinggi Filsafat Jaffray Makassar.

\section{Metode Penelitian}

Untuk mendapatkan data dan informasi berkaitan dengan skripsi ini, maka penulis menggunakan metode penelitian kuantitatif dengan beberapa model pengumpulan data sebagai berikut:

Pertama, angket, yakni membagikan angket kepada kaum muda di GKII Tumahoh Salap. Tujuannya untuk mendapatkan data yang lebih akurat tentang bagaimana mempersiapkan calon pemimpin melalui proses mentoring di kalangan kaum muda GKII Tumahoh Salap.

Kedua, wawancara, yakni penulis melakukan wawancara langsung dengan pengurus pemuda, dan anggota pemuda. Tujuannya untuk menguatkan data angket yang dibagikan kepada responden, sekaligus mengumpulkan informasi tentang proses mentoring yang telah dilakukan oleh GKII Tumahoh Salap.

Ketiga, studi kepustakan, yakni penulis mencari teori dan pernyataan untuk mendukung data melalui buku-buku yang ada di perpustakaan Sekolah Tinggi Filsafat Jaffray Makassar dan jurnal-jurnal dari internet yang berhubungan dengan skripsi ini.

\section{Batasan Penelitian}

Untuk penulisan skripsi ini, penulis memberi batasan penulisan. untuk membatasi ruang lingkup pembahasan yang diusulkan oleh penulis dalam skripsi ini, penulisan hanya berfokus pada mempersiapkan calon pemimpin melalui model mentoring dalam pengembangan karakter kepemimpinan di kalangan generasi muda GKII Tumahoh Salap.

\section{Sistematika Penulisan}

Penulisan skripsi ini disusun secara sistematis, untuk memudahkan pembahasan dalam penulisan skripsi ini adalah sebagai berikut:

Bab I, menguraikan pendahuluan dengan membahas latar belakang masalah, pokok masalah, tujuan penulis, metode penelitian, batasan penulisan, metode penelitian, batasan penulisan, manfaat penulisan, dan sistematika penulisan.

Bab II, menguraikan tinjauan pustaka yang terdiri atas: mentoring, Pengertian mentoring, pentingnya mentoring, prinsip mentoring, tujuan mentoring, keberhasilan mentoring dalam Alkitab, mentoring dalam Perjanjian Lama, mentoting dalam Perjanjian Baru, model mentoring antara lain: personal mentoring dan mentoring group, bentuk mentoring terdiri dari: mentoring pertemuan pribadi dan mentoring dalam penyelidikan Alkitab, karakter kepemimpinan, pengertian karakter, pengertian karakter kepemimpinan, 
karakter kepemimpinan dalam Alkitab terdiri dari: karakter kepemimpinan Perjanjian Lama antara lain, karakter kepemimpinan, karakter kepemimpinan Perjanjian Baru, indikator karakter kepemimpinan antara lain: kasih, integritas, kerendahan hati, kesabaran didalamnya ada penguasaan diri dan senang diajar, keberanian dan dampak mentoring dalam pemgembangan karakter kepemimpinan.

Bab III, metodologi penelitian yang membahas: gambaran umum lokasi penelitian, sejarah berdirinya GKII Tumahoh Salap, jenis penelitian, Teknik pengumpulan data, dan Teknik analisis data.

Bab IV, membahas mengenai analisis hasil penelitian dan pembahasan.

Bab V, merupakan bab kesimpulan dan saran.

\section{Kesimpulan}

Berdasarkan uraian dan analisis yang telah dikemukakan pada bab-bab sebelumnya, maka hasil penelitian ini dapat disimpulkan sebagai berikut:

Pertama, hasil analisis menunjukan bahwa bentuk mentoring pribadi $X_{1}$ memengaruhi indikator $\mathrm{Y}_{3}$ paling besar dari antara bentuk mentoring pribadi, yaitu $90,41 \%$. Pada bentuk mentoring $X_{2}$ memengaruhi indikator $Y_{2}$ juga $X_{2}$ memengaruhi indikator $\mathrm{Y}_{4}$ paling besar dari bentuk mentoring kelompok, yaitu sama-sama 89,16\%. Hal ini menunjukan bahwa kedua bentuk mentoring ini memengaruhi karakter kaum muda gereja GKII Tumahoh Salap.

Kedua, penggunaan bentuk mentoring pribadi memengaruhi dalam pertumbuhan pengembangan karakter kaum muda dalam sikap mengasihi kepada Tuhan, mengasihi orang yang mengecewakan, bertanggung jawab pada perkataan, menerima diri sendiri, dapat menolak pergaulan buruk, berani mengambil keputusan, berani memimpin kelompok dan sabar sehingga dapat menguasai diri sendiri. Berdasarkan hasil analisis ini menunjukan bahwa kaum muda ini memiliki karakter yang baik melalui proses mentoring pribadi.

Ketiga, dalam bentuk mentoring kelompok juga memengaruhi karakter kaum muda ini dalam sikap mengasihi kepada sesama, memberi pertolongan, mengambil keputusan untuk menjadi pelaku firman, berkomitmen merubah kebiasaan buruk, dapat menerima teguran orang lain, dapat menegur teman dengan teguran positif, menerima keadaan orang lain dan dapat mengakui kesalahan. Analisis ini menunjukan karakter kaum muda ini dapat terbentuk melalui mentoring kelompok.

Keempat, berdasarkan analisis, mentoring ini memengaruhi kepribadian kaum muda GKII Tumahoh Salap, terlihat melalui mentoring yang dilakukan, kaum muda dapat memimpin pribadi mereka dan dapat memimpin anggota kaum muda yang lainnya. Hasil inilah yang menunjukan bahwa mentoring ini dapat memengaruhi karakter kaum muda menjadi lebih baik.

\section{Saran-saran}

Berdasarkan hasil penelitian ini, maka penulis menguraikan beberapa saran kepada gereja GKII Tumahoh Salap, penulis berharap saran ini dapat bermanfaat dan dilaksanakan. Saran yang ingin dipaparkan adalah sebagai berikut:

Pertama, disarankan kepada kaum muda GKII Tumahoh Salap untuk setia mengikuti kegiatan-kegiatan yang dilakukan oleh pengurus pemuda untuk menumbuhkan iman dan karakter yang lebih baik.

Kedua, kepada pengurus pemuda untuk memikirkan hal-hal yang baru untuk lebih lagi melibatkan kaum muda dalam kegiatan-kegiatan umum gereja, sehingga karakter kepemimpinan itu tidak hanya terlihat dalam kegiatan kaum muda, tetapi juga dalam kegiatan gereja pada umumnya. 
Ketiga, kepada gembala dan BPJ agar melibatkan diri dalam kegiatan mentoring, dan menjadikan mentoring ini sebagai program gereja untuk mempersiapkan calon pemimpin kedepannya, sehingga mentoring ini tidak hanya berlangsung pada kegiatan kaum muda, tetapi terlihat dan tertulis dalam program gereja.

Keempat, kepada gembala, BPJ dan pengurus pemuda, agar dapat menjadikan mentoring ini sebagai kebutuhan gereja untuk terus mempersiapkan calon pemimpin untuk gereja dihari mendatang, dengan gereja mengoleksi buku-buku mentoring dan melakukan pelatihan bagi calon pemimpin yang dipersiapkan oleh gereja.

\section{Kepustakaan}

Afriantoni. Prinsip-Prinsip Pendidikan Akhlak Generasi Muda: Percikan Pemikiran Ulama Turki Bediuzzaman Said Nursi. Jakarta: Deepublish, 2015.

Agung, A. M. Lilik. Managing People: Kiat Praktis Mengelola Manusia bagi Supervisor. Jakarta: Elex Media Komputindo, 2014.

Allen, Matthew. "Models of Mentoring." Diakses 3 Juli 2019. https://faculty.medicine.iu.edu/let-us-help/mentoring/mentoring-matters/models-ofmentoring/.

Anastasia, Zetya Inger. "Visi Jemaat GMIT Pola Tribuana Kalabahi terhadap Pemberdayaan Pemuda dari Perspektif Pembinaan Pemuda." Skripsi, S.Si.Teo, Universitas Kristen Satya Wacana, 2017. http://repository.uksw.edu/handle/123456789/13413.

Chandra, Robby I. Pemimpin dan Mentoring dalam Organisasi. Jakarta: Generasi Info Media, 2006.

Cherone, Dylan. "Mentoring Dalam Proses Suksesi Kepemimpinan Bisnis Keluarga Pada CV. 369 Tobacco.” Agora 2, no. 2 (2014): 64-71.

Dubois, David L, Michael J. Karcher. Handbook of Youth Mentoring. America: Sage, 2005.

Fransisca, Delvy dan Yunus D. A. Laukapitang. "Kepemimpinan Yosia Berdasarkan Kitab 2 Tawarikh 34:1-7 dan Implikasinya bagi Pelayanan Pemuda di Gereja." Jurnal Ilmu Teologi dan Pendidikan Agama Kristen 1, no. 2 (Desember 2020): 103-122. http://dx.doi.org/10.25278/jitpk.v1i2.508.

Frederik, Hanny. "Prinsip-prinsip Kepemimpinan Penggembalaan Berdasarkan Yohanes 10:1-21 dan Implementasinya dalam Kepemimpinan Gereja." Jurnal Ilmu Teologi dan Pendidikan Agama Kristen 1, no. 2 (Desember 2020): 69-86. https://ojs.sttjaffray.ac.id/jitpk/article/view/487.

Greene, Rebecca. Belajar Tak Hanya Di Sekolah. Jakarta: ESENSI Erlangga Group, 2006.

Hakhiardy, Robbi. "Pola komunikasi pengurus Lembaga Dakwah Sekolah (LDS) dalam kegiatan mentoring di SMA Negeri 5 Depok." (Skripsi, S.Kom.I, Fakultas Ilmu Komunikasi, 2015). http://repository.uinjkt.ac.id/dspace/handle/123456789/27627.

Hartiti, Ike Puspitaningrum \& Tri. Peningkatan Kualitas Personal dan Profesional Perawat melalui Pengembangan Keprofesian Berkelanjutan (PKB). Yogyakarta: Budi Utama, 2017.

Hull, Bill. Choose The Life Memilih hidup Serupa Yesus Mengalami Transformasi Iman Melalui Pemuridan. Jawa Timur: Literatur Perkantas Jawa Timur, 2012.

Hutabarat, Herdy Natasha. Mentoring dan Pemuridan. Bandung: Kalam Hidup, 2011. Kartono, Kartini. Psikologi Anak (Psikologi Perkembangan). Jakarta: Mandar Maju, 1990.

Lewis, Rodger. Karya Kristus Di Indonesia Sejarah Gereja Kemah Injil Sejak 1930. Bandung: Kalam Hidup, 2014. 
Mogensen, Ranae. "What Is Group Mentoring?" 2012. https://www.managementmentors.com/about/corporate-mentoring-matters-blog/bid/80030/What-is-GroupMentoring.

Mulyasa, E. Manajemen Pendidikan Karakter. Jakarta: Bumi Aksara, 2014.

Munaqasyah, Sidang. “Analisis Pelaksanaan Mentoring.” Skripsi, S.Sos.I, Dakwah dan Komunikasi, 2009. https://respository.uinjkt.ac.id.

Noor, Juliansyah. Metodologi Penelitian: Skripsi, Tesis, Disertasi \& Karya Ilmiah. Jakarta: Kencana, 2017.

Octavianus, Jonathan. "Transisi Kepemimpinan Dalam Alkitab.” Journal Kerusso 1, no. 1 (2016): 16-38. https://doi.org/10.33856/kerusso.v1i1.44.

Phillips-Jones, Linda. "Group Mentoring - Max Power of Career Development." https://mentoringgroup.com/essentials-of-mentoring-groups-1.html.

Prihanto, Agus. "Peran Proses Mentoring Pemimpin Kaum Muda Bagi Perkembangan Pelayanan Pemuda di Gereja." Jurnal Jaffray 16, no. 2 (2018): 197-212.

Ronda, Daniel. Belajar Menjadi Pemimpin. Tangerang: Matana Publishing Utama, 2015. . Leadership Wisdom Antopologi Hikmat Kepemimpinan. Bandung: Kalam Hidup, 2015.

Rumahlatu, Jerry. Psikologi Kepemimpinan. Jakarta: Cipta Varia Sarana, 2011.

Sarosa, Pietra. Becoming young entrepreneur: dream big start small, act now! Jakarta: Elex Media Komputindo, 2006.

Sembiring, Ngendam. "Mengatasi Degradasi Moral Melalui Pembinaan Warga Gereja." Illuminate: Jurnal Teologi dan Pendidikan Kristiani 1, no. 1 (1 September 2018): 22-42.

Sodik, Sandu Siyato, dan Muhamad Ali. Dasar Metodologi Penelitian. Yogyakarta: Literatur Media Publising, 2015.

Sutrisno, Wiriadi, dan Suwiryo Cokro. "Analisis Pengaruh Edupreneurship Dan Mentoring Terhadap Peningkatan Daya Saing Lulusan Perguruan Tinggi." Research And Development Journal Of Education 5, No. 1 (2018): 114-24. https://journal.lppmunindra.ac.id/index.php/RDJE/article/view/3392.

Suwu, Reinold. Suksesi Kepemimpinan Rohani Menurut Alkitab. Bandung: Kalam Hidup, 2013.

Tacoy, Selvester M. 6 Kunci Sukses Melayani Kaum Muda. Bandung: Kalam Hidup, 2009.

Tambunan, Fernando. "Membangun Karakter Kepemimpinan.” Jurnal Teologi Illuminare 1, no. 2 (2014): 1-21.

Tri, Sutrisno, dan Baidi. "Pelaksanaan Ekstrakurikuler Mentoring Rohani Islam (Rohis)Dalam Meningkatkan Kecerdasan Spiritual siswa Kelas X di SMA Negeri 1 Gemolong Tahun Ajaran 2017/2018." Skripsi S.Pd.I, Fakultas Ilmu Tarbiyah dan Keguruan IAIN Surakarta, 2017. http://eprints.iain-surakarta.ac.id/1146/.

Wahyuni, Tri. "Mentoring Sebagai Upaya Meningkatkan Pengetahuan Wus Tentang Gizi Seimbang 1000 Hari Pertama Kehidupan (1000 HPK) (Studi kasus di wilayah Kelurahan Purwoyoso Semarang).” Skripsi S.KM, Universitas Negeri Semarang, 2015. https://lib.unnes.ac.id/23335/.

Widiyanto, Mikha Agus. Statistika untuk Penelitian Bidang Teologi, Pendidikan Agama Kristen \& Pelayanan Gereja: Lengkap dengan Konsep dan Aplikasi SPSS. Bandung: Kalam Hidup, 2014.

Wijaya (ed), Hengki. Metodologi Penelitian Pendidikan Teologi. Makassar: Sekolah Tinggi Theologia Jaffray, 2016.

Yanto, Arief, Andrew Johan, dan Sri Rejeki. "The Relation Between The Application of Mentoring And The Level Of Work Stress Of The New Graduate Nurses In SMC 
Telogorejo Hospital Semarang.” Tesis, M.Kep, Fakultas Kedokteran Diponegoro Universitas Semarang, 2016. http://eprints.undip.ac.id/47753/.

Yeakley, Tom. Character Formation for Leaders 10 Kualitas Karakter yang Harus

Dimiliki Pemimpin Kerajaan Allah. Bandung: Kalam Hidup, 2013.

Zschech, Darlene. The Art of Mentoring Mewariskan Konsep Nilai kepada Generasi Muda. Malang: Literatur SAAT, 2013. 